\title{
Caspase-7 deficiency in Chinese hamster ovary cells reduces cell proliferation and viability
}

\author{
Fatemeh Safari ${ }^{1,3}$, Safar Farajnia ${ }^{2,7^{*}}$, Abbas Behzad Behbahani ${ }^{3}$, Habib Zarredar ${ }^{4}$, Mazyar Barekati-Mowahed ${ }^{5}$ \\ and Hesam Dehghani ${ }^{6}$
}

\begin{abstract}
Background: Chinese hamster ovary (CHO) cells are the most commonly used mammalian host cell in the commercial-scale production of biopharmaceutical proteins. Modification of genes involved in apoptosis may improve the productivity of $\mathrm{CHO}$ cells. Executive caspases, including caspases 3 and 7, play critical roles in apoptosis. The effects of the ablation of the caspase 7 gene on proliferation and viability of $\mathrm{CHO}$ cells remains unknown. In this study, we applied clustered regularly interspaced short palindromic repeat (CRISPR/Cas9) to target caspase 7 gene of CHO K1 cell via all in one and homology targeted integration strategies. Consequently, the effect of caspase 7 deficiency on cell proliferation, viability, and apoptosis was studied by MTT assay and flow cytometry.
\end{abstract}

Results: Findings of gel electrophoresis, western blotting, and sequencing confirmed the caspase 7 gene silencing in $\mathrm{CHO}$ cells (CHO-KO). Proliferation assay revealed that caspase 7 deficiency in $\mathrm{CHO}$ cells resulted in the reduction of proliferation in various $\mathrm{CHO}-\mathrm{KO}$ clones. Besides, the disruption of caspase 7 had negative effects on cell viability in exposure with NaBu which confirmed by MTT assay. Results of flow cytometry using Anexin V/PI demonstrated that Nabu treatment $(11 \mathrm{mM})$ declined the percentage of live $\mathrm{CHO}-\mathrm{K} 1$ and $\mathrm{CHO}-\mathrm{KO}$ cells to $70.3 \%$ and $5.79 \%$. These results verified that the $\mathrm{CHO}-\mathrm{K} 1$ cells were more resistant to apoptosis than $\mathrm{CHO}-\mathrm{KO}$, however most of $\mathrm{CHO}-\mathrm{KO}$ cells undergone early apoptosis (91.9\%) which seems to be a fascinating finding.

Conclusion: These results reveal that caspase 7 may be involved in the cell cycle progression of $\mathrm{CHO}$ cells. Furthermore, it seems that targeting caspase 7 is not the ideal route as it had previously been imagined within the prevention of apoptosis but the relation between caspase 7 deficiency, cell cycle arrest, and the occurrence of early apoptosis will require more investigation.

Keywords: CHO cells, Apoptosis, CRISPR-associated protein 9, Caspase 7, Cell proliferatio

\section{Background}

Chinese hamster ovary $(\mathrm{CHO})$ cells are the most commonly used cells for stable gene expression and producing heterologous proteins [1]. About 35\% of recombinant proteins that are currently approved for

\footnotetext{
*Correspondence: farajnias@tbzmed.ac.ir

${ }^{2}$ Biotechnology Research Center, Tabriz University of Medical Sciences, Daneshgah Ave., Tabriz, Iran

Full list of author information is available at the end of the article
}

human therapeutic use are produced in $\mathrm{CHO}$ cells [2]. Hence, the improvement of this mammalian expression system to achieve higher productivity and quality is of great industrial interest [3].

The low volumetric yield of protein is a significant challenge in the mammalian cell expression system, which is associated with a slower growth rate and high death rate of mammalian cells [4]. To respond to the market demands, cells have to be grown in large bioreactors at high densities during a prolonged period [4]. Cell culture 
(See figure on next page.)

Fig. 1 The schematic of CRISPR HITI. a In this strategy, two donor vectors without homology arms were utilized. These donner vectors contain sgRNA + PAM and EGFP expression cassette. In the guide of two sgRNAs, the Cas 9 protein towards the exons 4 and 5 of CASP-7 at both alleles. Endonuclease function of Cas9 results in the deletion of a genomic fragment (between the exon 4 and 5) from both alleles, and the linearization of two donor vectors. The selection of cells for green color leads to the generation of caspase 7 knocked out cells. $\mathbf{b}$ The presentation of the HITI method, which uses NHEJ-mediated targeted integration in combination with Cas9 nuclease activity. If the target site remains intact or with integration in the reverse direction, DNA bears additional cleavage since forward gene insertion or gRNA can no longer bind to the target site through errors from the NHEJ repair system. c The schematic of PX460-1 vector which contains a single cloning site for bait gRNA and the expression cassette of the EGFP gene

in high density leads to environmental perturbations and cell stress due to the limitation of nutrients and oxygen, and accumulation of toxic metabolites [5].

Intense and continuous stress leads to cell death by one of the two mechanisms of passive cell death called necrosis, and apoptosis as programmed cell death. Cell death via apoptosis is identified with specific morphological characteristics and activation of a variety of cellular signaling cascades [6]. Diverse cell signaling cascades that originate as the extra- or intra-cellular stimuli can activate death-inducing pathways, downstream of caspase effectors. Caspases are divided into the inflammatory caspases and the apoptotic caspases. Apoptotic caspases are further divided into initiators. (caspases 8, 9, 10, and 12 ) and executors (caspases 3, 6, and 7). Initiator caspases activate executor caspases, which in turn cleave critical cellular substrates and lead to the apoptotic morphological changes [7]. Findings suggest that caspases 3 and 7 have dominant functions in apoptosis. Thereby, caspase 3 can inhibit ROS production and is an essential effector for efficient cell killing, while caspase 7 is responsible for cell detachment and ROS production [8]. Research findings show that the downregulation of caspases 3 and 7 in $\mathrm{CHO}$ cells promotes production while impeding apoptosis.

Various genetic engineering strategies have been established to improve the growth rate of host cells and their final yield. Thus, generating desirable genomic traits in $\mathrm{CHO}$ cell lines is one of the highly valuable strategies. Genome editing strategies have been traditionally performed using conventional methods such as random mutagenesis [9], homologous recombination and downregulation using siRNA $[10,11]$. Nevertheless, the low frequency of desirable mutagenesis and spontaneous cleavage of chromosomal DNA led scientists to use site-specific nucleases [12]. Site-specific nucleases such as zinc-finger nucleases (ZFNs) [13], transcription activator-like effector nucleases (TALENs) [14], meganucleases [15], and the more recent clustered regularly interspaced short palindromic repeats (CRISPR)/CRISPR-associated (Cas) system [16-19], have opened a promising window for rapid and efficient gene editing at defined genomic sites. Site-specific nucleases employ different doublestrand DNA break repair strategies including the nonhomologous end joining (NHEJ), or homology-directed repair (HDR) [20-22].

In various studies, the CRISPR/Cas9 system has been applied to modify cell cycle-related genes, especially those involved in apoptosis. Triple knockout $\mathrm{CHO}$ cell lines which were attained by simultaneous disruption of FUT8, BAK, and BAX in a multiplexing setup, showed higher resistance to apoptosis [23]. Since executive caspases play significant roles in apoptosis, herein, we used CRISPR-assisted genome editing to knock out the caspase 7 gene (CASP-7). We used the multiplex CRISPR system and homology independent targeted integration (HITI) strategy to disrupt the CASP-7. Thereafter, we assessed the effects of this gene knock out on cell proliferation, viability, and apoptosis in both $\mathrm{CHO}$ cells.

\section{Results}

\section{Application of CRISPR HITI mediated knockout strategy for targeting CASP-7}

To target the active site of caspase 7 , we aligned the sequence of this protein with the human caspase 7 sequence. Findings showed that the active site of $\mathrm{CHO}$ caspase 7 is flanked by exon 4 and 5 . To target the active site of caspase 7 , we used the "CRISPR HITI" strategy aiming for the deletion of a genomic fragment encompassing exon 4 and 5 using two sgRNAs and simultaneous insertion of a reporter (Fig. 1). After the first round of transfection, single cells were isolated by cell sorting and expanded a clone of cells that were permanently expressing EGFP (Fig. 2). The correct location of knock-in was confirmed by PCR analysis of genomic DNA. In this PCR we used a forward genomic primer and a PX460-1 reverse primer to show the integration of EGFP cassette in CASP-7. To verify the homozygosity of the clone, another PCR was performed for both wild-type (CHO$\mathrm{K} 1)$ and knockout cells (CHO-KO) using genomic primers (Fig. 3a). The Homozygote clone did not produce the PCR product, because the length of the integrated DNA fragment was more than 5000 bp which is not amplifiable by regular Taq polymerase, but the heterozygote clone 
$\mathbf{a}$

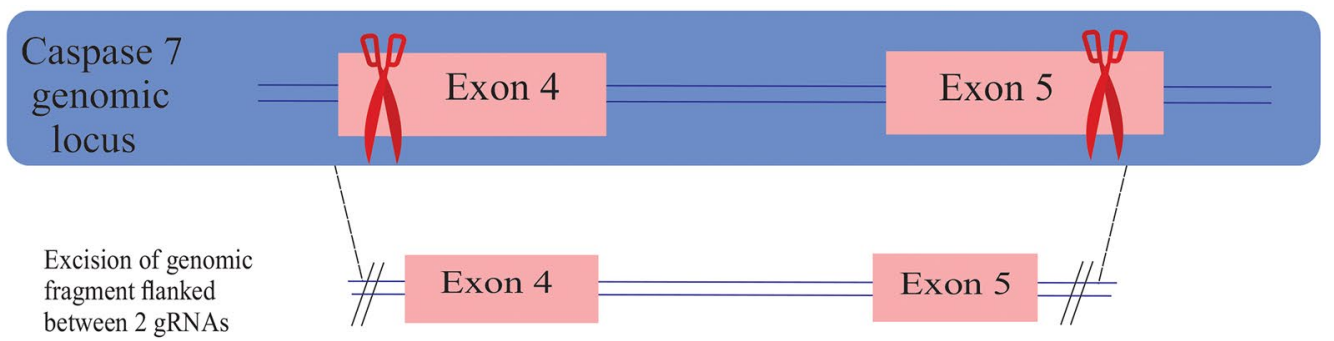

The replacement of genomic segment with donner vector

Integration of EGFP cassette in the site of excision in both alleles

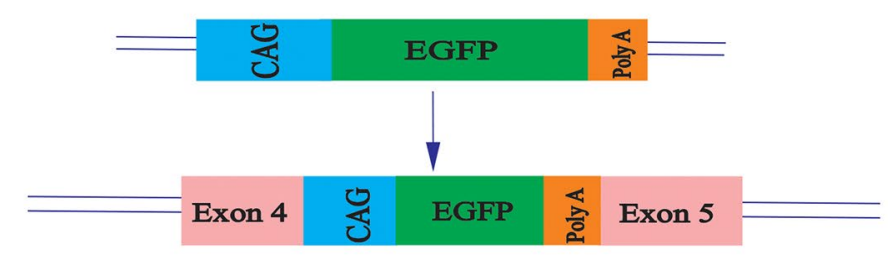

b Genomic DNA cleavage site
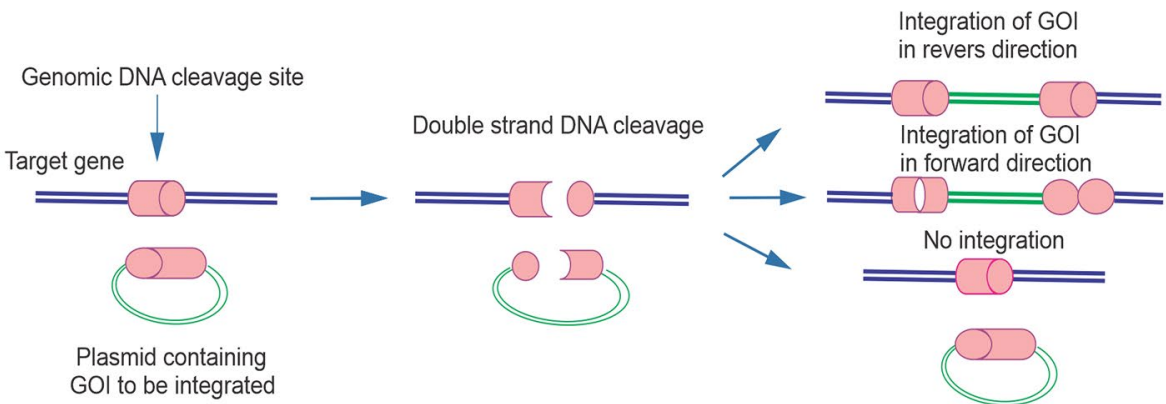
Plasmid containing
$\mathrm{GO}$ to be integrated

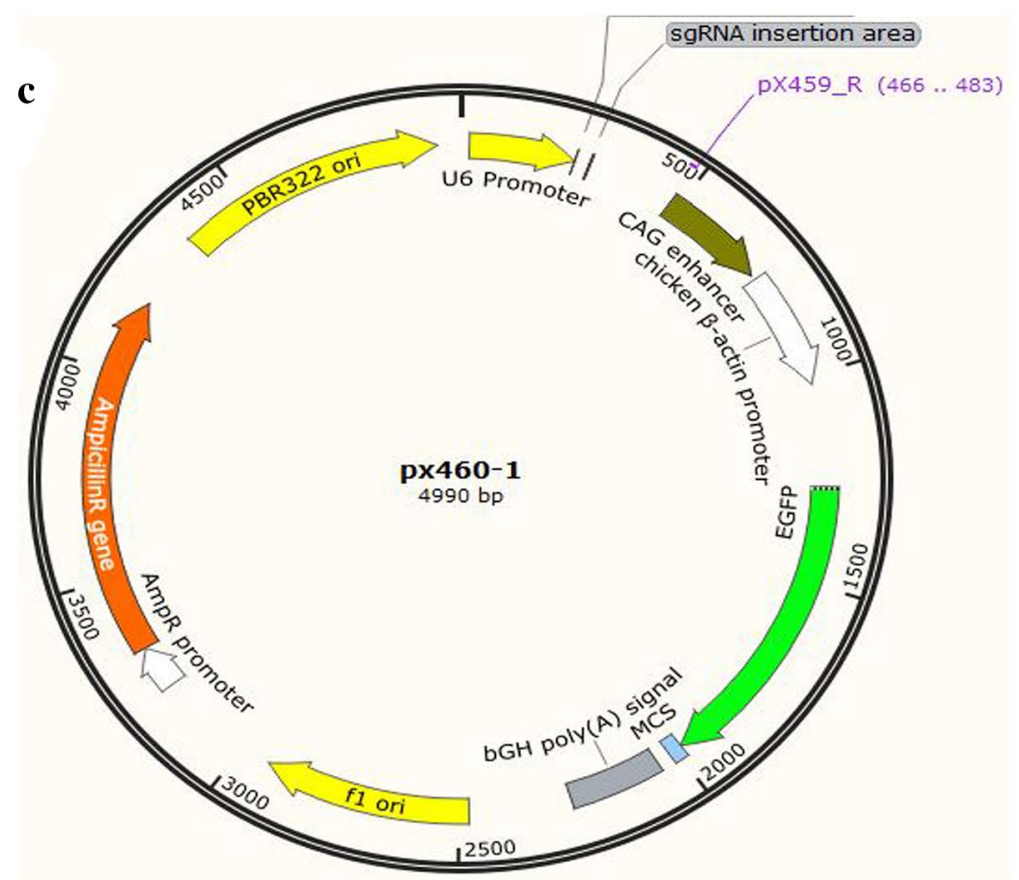


a

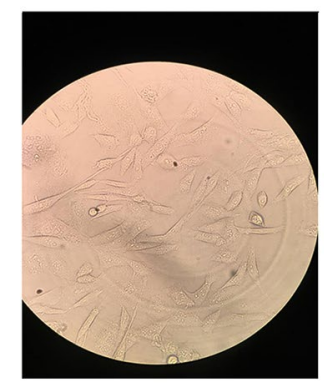

b

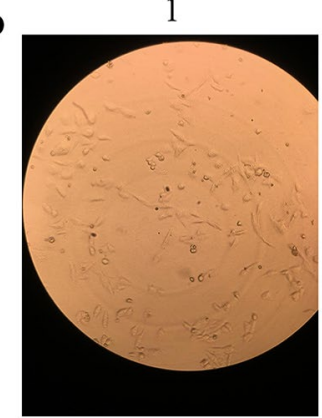

2

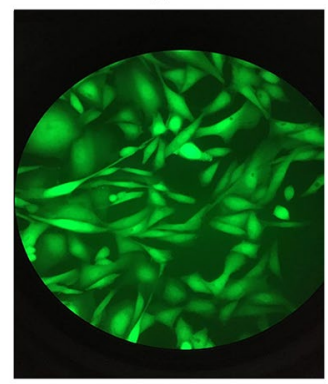

2

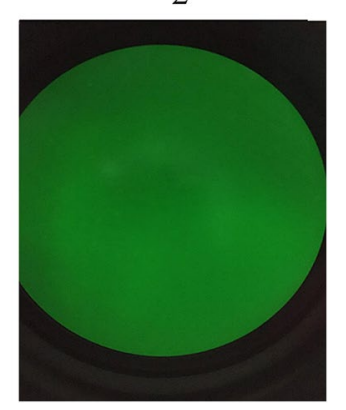

Fig. 2 The clonal selection of EGFP expressing $\mathrm{CHO}$ cells. a1 The picture of permanent EGFP expressing $\mathrm{CHO}$ cells (CHO-KO) on the visible light of an inverted microscope. a2 The picture of permanent EGFP expressing $\mathrm{CHO}$ cells (CHO-KO) on the fluorescent light of an inverted microscope. b1 The picture of native $\mathrm{CHO}$ cells (CHO-K1) on the visible light of the inverted microscope. $\mathbf{b 2}$ The picture of native $\mathrm{CHO}$ cells ( $\mathrm{CHO}-\mathrm{K} 1)$ on the fluorescent light of the inverted microscope

and native $\mathrm{CHO}-\mathrm{K} 1$ produced a $580 \mathrm{bp}$ band. The $310 \mathrm{bp}$ PCR product had been used for sequencing which confirmed the integration of EGFP (Fig. 3c). Furthermore, caspase 7 deficiency of $\mathrm{CHO}-\mathrm{KO}$ cell was verified by western blotting (Fig. 3b).

\section{Caspase 7 deficiency negatively affected the proliferation and viability of $\mathrm{CHO}-\mathrm{KO}$ cells}

Cell proliferation and cell viability are two determinant factors that affect cell productivity. To assess the $\mathrm{CHO}-\mathrm{KO}$ cell growth, we used the cell proliferation assay in which the number of live cells was estimated in 5 days by measuring the absorbance of MTT for $\mathrm{CHO}-$ $\mathrm{K} 1$ and $\mathrm{CHO}-\mathrm{KO}$ cells. The result of the cell proliferation assay showed that the silencing of the CASP-7 has lowered the proliferation of $\mathrm{CHO}-\mathrm{KO}$ by up to $30 \%$ (p-value $<0.0001$ ) (Fig. 4a). To confirm this difference and to eliminate the effect of $\mathrm{CHO}$ cell heterogeneity on cell proliferation, 4 single cell clones were isolated from the parentral $\mathrm{CHO}-\mathrm{KO}$ cells and repeated the cell proliferation assays in 1 and 5 days ( $\mathrm{p}$-value: Clone $1=0.0006$, clone $2=0.0025$, clone $3<0.0001$, clone $4<0.0001$ ) (Fig. 4b). These findings confirmed the involvement of caspase 7 in cell proliferation of $\mathrm{CHO}$ cells.

Sodium butyrate $(\mathrm{NaBu})$ is a histone deacetylase inhibitor, which increases the expression of therapeutic proteins in dose-dependent manner (0.5 to $5 \mathrm{mM})$. But at these concentrations, $\mathrm{NaBu}$ induces cytotoxicity due to the inhibition of cell growth and gene expression [24, 25]. Hence, to increase productivity without the irreversible cytotoxic effects, $\mathrm{NaBu}$ utilization must be highly controlled. Massive application of $\mathrm{NaBu}$ in increasing the recombinant protein productivity in $\mathrm{CHO}$ cells, introduces this compound as a proper apoptosis inducer in this cell line. Therefore, in this study, we used $\mathrm{NaBu}$ as an apoptosis inducer to investigate the apoptosis resistance of $\mathrm{CHO}-\mathrm{KO}$ cells. The viability of $\mathrm{CHO}-\mathrm{KO}$ cells was investigated by MTT assay using $\mathrm{NaBu}(5,7,9$, and $11 \mathrm{mM}$ ) for 1, 2, 3, and 5 days (Fig. 5) which was repeated three times and in sextuplicate for each concentration of $\mathrm{NaBu}$. Statistical analysis using ANOVA test showed that the silencing of caspase 7 reduced the viability of CHO-KO cells in comparison with wild type CHO-K1. ( $p$-value: day $1=0.0001$, day $2=0.0089$, day $3=0.0138$, day $5=0.0003$ ).

Analysis of these findings showed that the reduction of $\mathrm{CHO}-\mathrm{KO}$ cell viability, in addition to $\mathrm{NaBu}$ cytotoxicity may be due to its lower cell proliferation. Because the MTT assay only demonstrates the percentage of live cells, while the same concentration of $\mathrm{CHO}-\mathrm{K} 1$ and $\mathrm{CHO}-\mathrm{KO}$ cells were seeded, the lower proliferation of $\mathrm{CHO}-\mathrm{KO}$ cells affected the percentage of these cells viability.

\section{Knockout of caspase 7 does not improve resistance to apoptosis}

Flow cytometry was performed to measure the number of cells that have undergone apoptosis. Considering that Annexin V is mostly conjugated to FITC, apoptosis detection in EGFP-expressing cells can be problematic. Therefore, in this study AnnexinV/PI was used to minimize the spectral overlap between the emission profiles of FITC and EGFP fluorophores. In this assays, the negative control and $\mathrm{NaBu}$-treated cells of both $\mathrm{CHO}-\mathrm{K} 1$ and $\mathrm{CHO}-\mathrm{KO}$ groups were assessed two times. Both cell lines were treated with $\mathrm{NaBu}$ for 5 days, with a concentration of $11 \mathrm{mM}$ (Fig. 6). The findings of these assays are demonstrated in Fig. 5 which revealed that $94.17 \%$ of $\mathrm{CHO}$ $\mathrm{KO}$ cells have undergone apoptosis. But only $25.2 \%$ of $\mathrm{CHO}-\mathrm{K} 1$ cells were affected by apoptosis. These findings displayed that the $\mathrm{CHO}-\mathrm{K} 1$ cells were more resistant to apoptosis than $\mathrm{CHO}-\mathrm{KO}$ cells. The early apoptosis occurrence in $91.9 \%$ of $\mathrm{CHO}-\mathrm{KO}$ cells was a fascinating event that requires more investigation. 
a

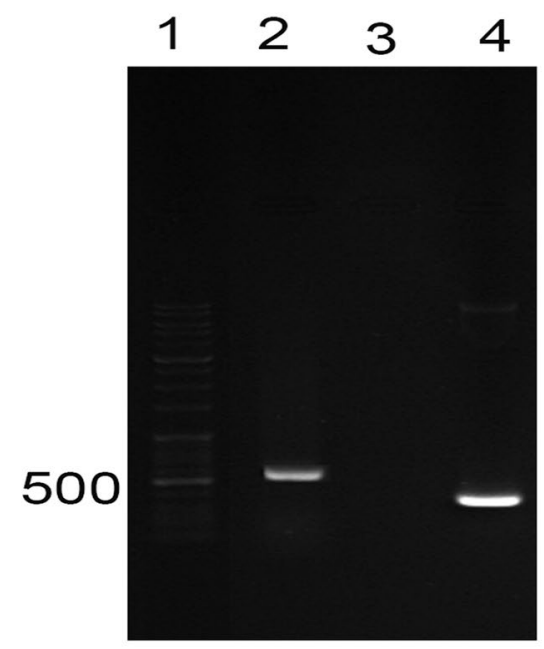

b

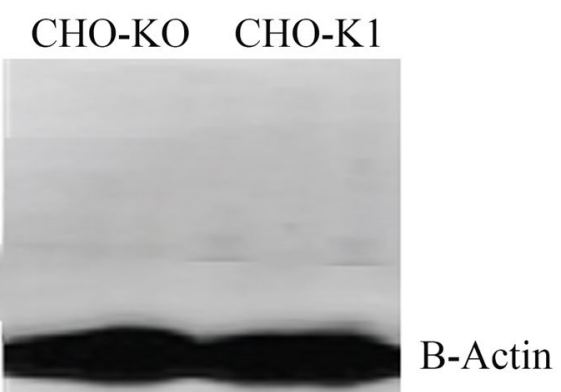

$33 \mathrm{KD}$

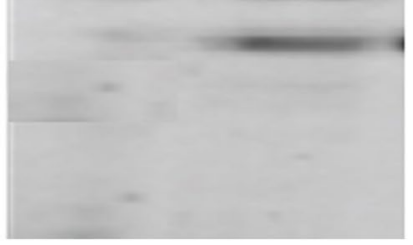

\section{Caspase 7}

c
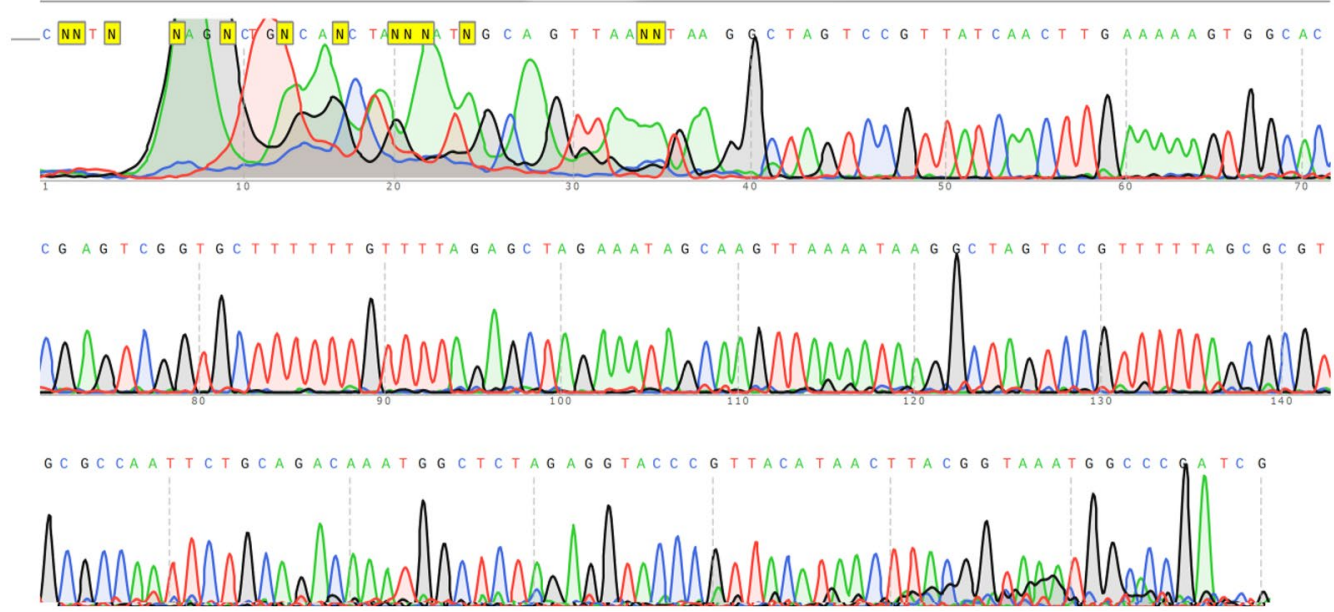

Fig. 3 The presentations of gel electrophoresis, western blotting, and sequencing. a Gel electrophoresis of PCR products of both CHO-K1 (as control) and CHO-KO. Lane 1: ladder, lane 2: the PCR product of CHO-K1 using genomic primers (5' CTGAGGAGGACCACAGCAACTC and 5' AACTGT GGAGTAAGCGAAGAGAA), which produced a 580 bp band. Lane 3: the PCR product of CHO-KO using genomic primers (this PCR did not produce any band because the PCR product must be more than $5000 \mathrm{bp}$, which was not amplifiable by regular Taq DNA polymerase). Lane 4: a $310 \mathrm{bp}$ PCR product produced by using caspase 7 genomic forward primer (5' CTGAGGAGGACCACAGCAACTC) and a piece of PX460-1 vector (5' CGGGCC ATTTACCGTAAGTTATGTAACG) as a reverse primer. This band confirmed the integration of EGFP in the targeted site of the CHO-KO genome. $\mathbf{b}$ The presentation of western blotting. As this figure showed the genomic disruption in caspase 7 of $\mathrm{CHO}-\mathrm{KO}$ cells resulted in the lack of producing of caspase 7 protein (33KD) in these cells. Beta actin was used as an endogenous control which expresses in both CHO-KO and CHO-K1 cells. c This picture depicts the sequencing of $310 \mathrm{bp}$ fragment contained a piece of the pX460-1 vector which verified the EGFP integration in the target site of caspase 7

\section{Discussion}

$\mathrm{CHO}$ cells are the popular mammalian workhorse for the production of commercial therapeutically essential proteins. The development of recombinant $\mathrm{CHO}$ cells has become a priority in biopharmaceutical manufacture [26]. Apoptosis is one of the $\mathrm{CHO}$ cell challenges in the broad-scale cell culture, which affects the yield of biopharmaceutics. Hence, developing methods to impede cell death in bioreactors has been followed with a great interest [27]. In the molecular signaling pathway, programmed cell death can be initiated from three main pathways, including the death mediated by a receptor, mitochondria, or ER stress. All these three pathways are terminated to the activation of initiator and executor caspases [7]. 
b

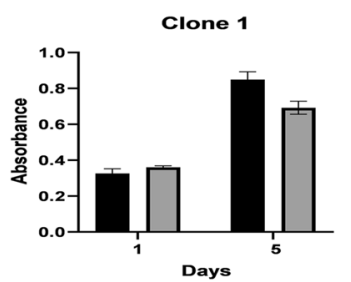

clone 3

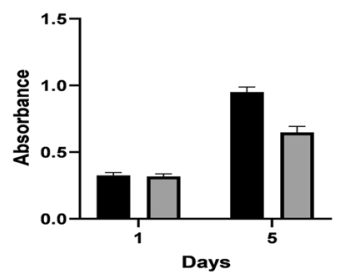

Cell proliferation assay

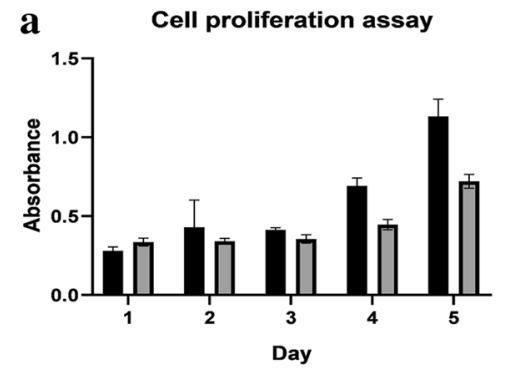

- CHO-K1 cell

口 $\mathrm{CHO}-\mathrm{KO}$ cell

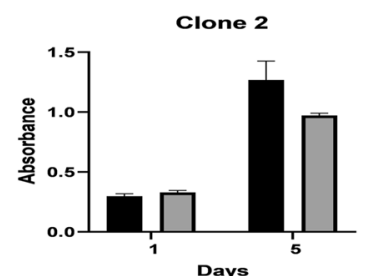

- CHO-K1 cells

[ CHO-KO cells

D CHO-K1 cells

Clone 4

- CHO-K1 cells

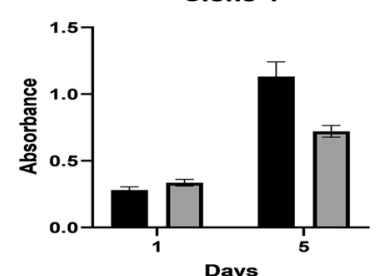

- $\mathrm{CHO}-\mathrm{K} 1$

ए CHO-KO

Fig. 4 Cell proliferation assays on CHO-KO parentral and single cell clones. a This graph represented the results of cell proliferation assay of parentral CHO-KO clone in 1,2,3 and 5 days. $\mathbf{b}$ This graph demonstrated the findings of cell proliferation assay of 4 single cell clones in 1 and 5 days. These results showed that the caspase 7 disruption interfered with the cell proliferation of $\mathrm{CHO}-\mathrm{KO}$ cells

By playing a vital role in executing caspase-dependent apoptosis, the caspases have become plausible targets for anti-apoptosis engineering. In the apoptosis, activated caspase- 3 is often translocated into the nucleus, whereas active caspase-7 is associated with the ER and mitochondrial membranes. Caspases 3, 7, 8, and 9 have been targeted in $\mathrm{CHO}$ cells by knock-down $[8,28-33]$ or via the overexpression of the caspase-inhibitors such as XIAPs or CRMA [24].

In this study, the CRISPR system has been applied to knockout the CASP-7 using all in one and HITI strategies. Results of cell proliferation assay revealed that the disruption of caspase 7 expression affected the cell cycle progression and reduced cell proliferation by up to $30 \%$.

It is the first report of the caspase 7 involvement in the $\mathrm{CHO}$ cell proliferation. These findings showed that besides playing a role in apoptosis, caspase 7 has noncanonical roles in proliferation and cell-cycle control. This area is less well-studied due to a few numbers of in vitro and in vivo studies which assessed the role of the caspases in cell cycle regulation. It has long been reported that cell-cycle proteins are substrates undergone proteolysis mediated by caspase 7 [34]. The examples of caspase-mediated cell-cycle proteins cleavage which causes their activation and/or translocation is $\mathrm{Rb}$ cleavage by caspase- 3 and -7 [35]. This cleavage results in the attachment of truncated Rb to cyclin D3 and reduces E2F1 transcriptional activity [36]. Cleavage of the CHK1 (checkpoint kinase) by caspase- 3 and -7 generates a truncated CHK1 with enhanced kinase activity $[37,38]$.

In addition, Hashimoto and his colleagues' reports showed that the silencing of caspase 7 by siRNA/shRNA resulted in cell cycle delay or arrest at the mitotic phase. Evidence of this study unveiled that during mitosis in HepG2 cells, activated caspase 3 is accumulated and also caspases 7, 8 and 9 partly become activated [39]. Also, transcriptomic studies revealed the myocyte proliferation reduction in the neonatal caspase 7 deficient heart [40]. Importantly, caspase- 7 deficiency in mutant mice led to significant defects in bone formation and reduction of bone volume, mineral content, and density [41]. However it needs more investigation, but it seems that caspase 7 deficiency in $\mathrm{CHO}$ cells may lead to cell cycle arrest due to a delay in mitotic phase.

To assess the apoptosis resistance of knockout cells, viability assay was performed using various concentrations of $\mathrm{NaBu}$. Butyrate works as a histone deacetylase inhibitor, which facilitates the relaxation of the 

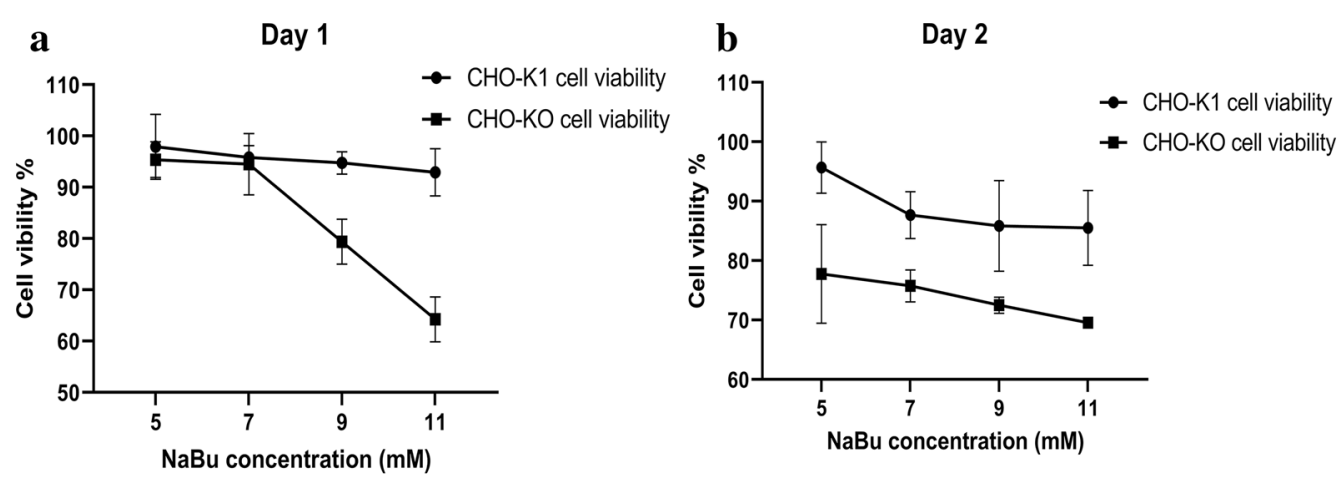

c

Day 3

\section{d}
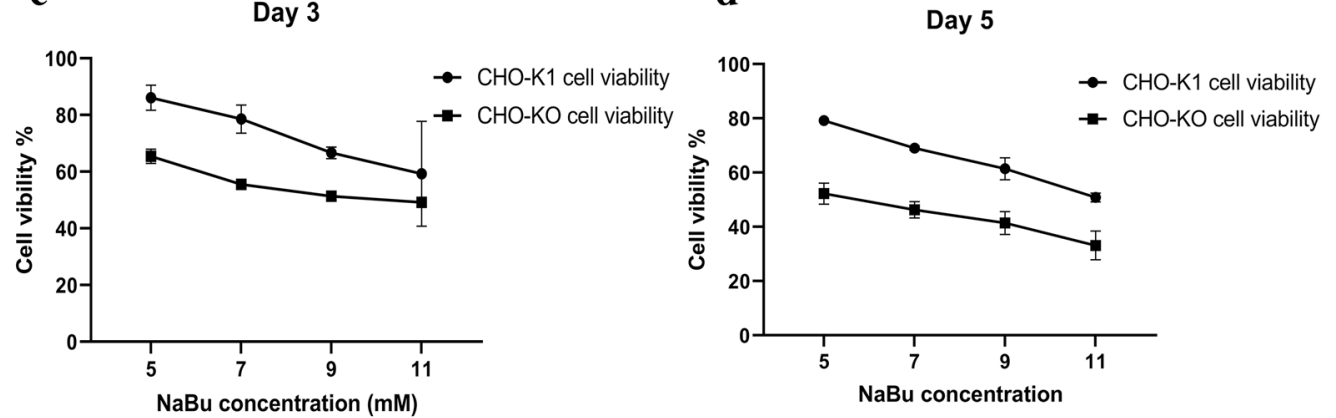

Fig. 5 Cell viability assay. a This graph represented the results of cell proliferation assay in 5 days, which showed that caspase 7 disruption interfered with the cell proliferation of $\mathrm{CHO}-\mathrm{KO}$ cells. $\mathbf{b}$ The assessment of $\mathrm{CHO}-\mathrm{K} 1$ and $\mathrm{CHO}-\mathrm{KO}$ cell viability using MTT assay (NABu was applied as an apoptosis inducer in concentrations of 5,7, 9, and $11 \mathrm{mM}$ ). a MTT assay after $24 \mathrm{~h}$ exposure with NaBu. b MTT assay after $48 \mathrm{~h}$ exposure with NaBu. c MTT assay after $72 \mathrm{~h}$ exposure with NaBu. d MTT assay after five days of exposure with NaBu. Overly these graphs demonstrated that caspase 7 deficiency worsens the apoptosis resistance of $\mathrm{CHO}-\mathrm{KO}$ in exposure with $\mathrm{NaBu}$

chromatin. It consequently increases the transcription of genes and amends the gene expression in $\mathrm{CHO}$ cells [42]. Nevertheless, this short-chain fatty acid induces both the extrinsic and intrinsic pathways of apoptosis [43]. Results of MTT assay unveiled that the CHO-KO cells were more susceptible to apoptosis induced by $\mathrm{NaBu}$ than CHO-K1 cells. Also, apoptosis assay using Annexin V/ PI confirmed the findings of MTT assay, which showed that knockout of caspase 7 led to undesirable effects on $\mathrm{CHO}-\mathrm{KO}$ cells. We saw that $\mathrm{CHO}-\mathrm{K} 1$ is more resistant than $\mathrm{CHO}-\mathrm{KO}$ to apoptosis induced by $\mathrm{NaBu}(11 \mathrm{mM}$ for 5 days). However, most $\mathrm{CHO}-\mathrm{KO}$ cells undergone early apoptosis which may be due to the role of caspase 7 in apoptosis-related mitochondrial events. In cells undergoing stress-induced apoptosis, mitochondria may act as amplifiers of caspase activity [44, 45]. It is reported that in double knockout (caspase 3 and 7 deficient) cells, early mitochondrial events such as cytochrome c release into the cytoplasm and Bax translocation to the mitochondria were both delayed [46]. However, the process of apoptosis induced by other pathways is continued, but a delay in mitochondrial events may preserve the apoptotic cells in the early apoptosis phase. Furthermore, it seems that in the early/intermediate state of apoptosis the mitochondria may remain intact which results in functional apoptotic cells [47]. These evidences may explain the differences of MTT and flow cytometry findings by which remaining mitochondria intact at early stages of apoptosis may reduce the potential of MTT assay to detect early apoptotic cells [48].

In line with these discoveries, findings of recent metaanalysis revealed that the knock-down of caspases 3 and 7 in $\mathrm{CHO}$ cells generally resulted in small improvements in viable cell density (up to 40\%) [33]. One of these studies reported the results with an outlier of 360\% [28]. The overexpression of XIAP and CRMA as the caspase inhibitors in cultures exposed to Sindbis virus (the apoptosis inducer) displayed similar culture dynamics to controls but with a consistently lower reduction rate in viability [49]. Another group found no substantial significance in culture or titer when $\mathrm{NaBu}$ was used to mediate apoptosis [24]. These conflicting results have been systematically assessed, and overall, it seems that targeting caspases, or their inhibitors, is imperfect than would be expected at preventing apoptosis from a 'caspase-centric' view. This may be related to the downstream role of caspase 

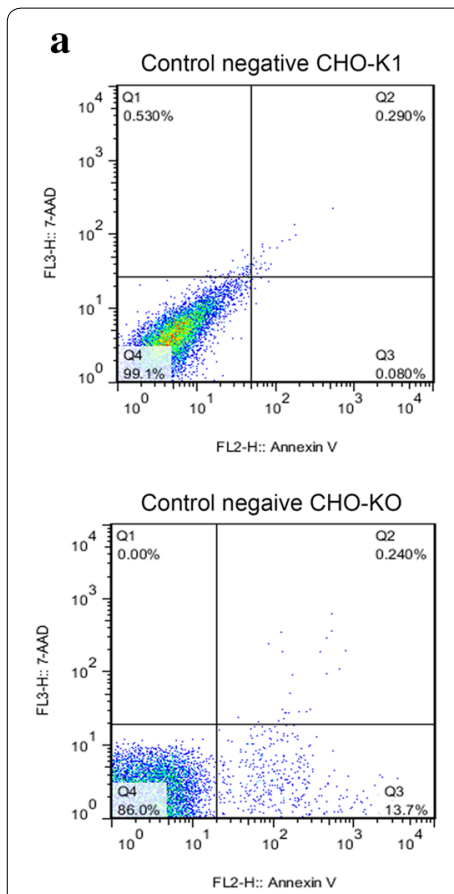
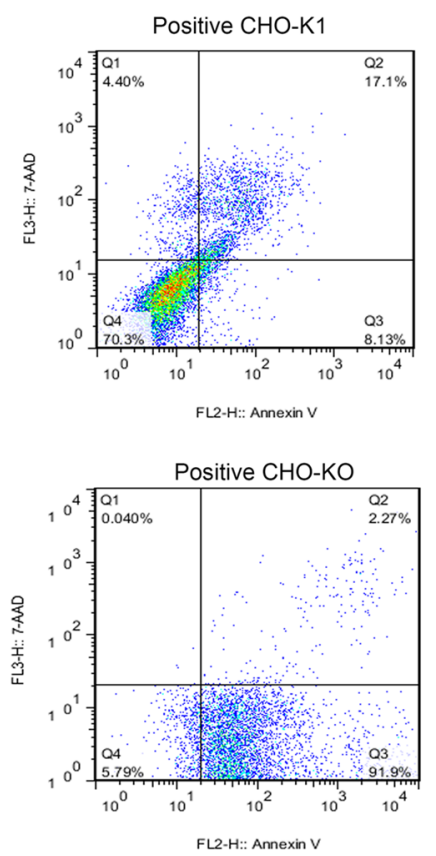

b

\begin{tabular}{|c|c|c|}
\hline Zones & Positive CHO-KI & Positive CHO-KO \\
\hline Necrosis & $4.40 \%$ & $0.040 \%$ \\
\hline Late apoptosis & $17.1 \%$ & $2.27 \%$ \\
\hline Early apoptosis & $8.1 \%$ & $91.9 \%$ \\
\hline Live cells & $70.3 \%$ & $5.79 \%$ \\
\hline
\end{tabular}

c

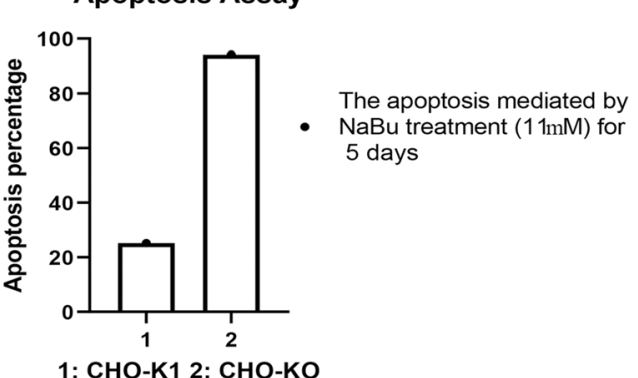

1: CHO-K1 2: CHO-KO

Fig. 6 Apoptosis assay using Annexin V/PI staining. In this assay, NaBu was used as an apoptosis inducer for five days at 11 mM concentration. a the presentation of apoptosis assay histogram for both $\mathrm{CHO}-\mathrm{K} 1$ and $\mathrm{CHO}-\mathrm{KO}$ cells. b A table contained the cell percentage of each histogram zone for both $\mathrm{CHO}-\mathrm{K} 1$ and $\mathrm{CHO}-\mathrm{KO}$ cells. c A columnar graph that comprised the percentage of apoptosis in $\mathrm{CHO}-\mathrm{K} 1$ and $\mathrm{CHO}-\mathrm{KO}$ cells. Altogether, they showed that $\mathrm{CHO}-\mathrm{KO}$ cell was more susceptible to apoptosis than $\mathrm{CHO}-\mathrm{K} 1$ in exposure with $\mathrm{NaBu}$

7, which means that cells may have already lost functionality (e.g. through MOMP) before the activation of caspases. Moreover, caspases are not involved in caspaseindependent apoptosis [50].

To disrupt the CASP-7, in this study the sgRNAs targeting exon 4 and exon 5 were designed and cloned in the all in one vector. Also, the HITI strategy was employed to make the clone selection easy using donner gRNAs and vectors. Recently, HITI, as a novel genome-editing technology, has been developed, which is a combination of the NHEJ repair mechanism with the CRISPR/Cas9 system. In the HITI strategy, donor plasmids lack homology arms. Consequently, repair of the Cas9-induced genomic DSB cannot occur through the HDR pathway. The donor DNA is designed to include the Cas9 cleavage site(s) that flanks beside the donor sequence. Cas9, therefore, cleaves both the genomic target sequence and the donor plasmid, thereby generating blunt ends associated with both target and donor sequences [51]. HITI donor vectors were constructed to ensure robust gene integration only when inserted in the forward direction. If inserted in the reverse direction or is unintegrated, the DNA would undergo further cleavage by Cas 9 until inserted correctly or gRNA is no longer able to bind to target sequences due to errors during NHEJ repair. The efficiency of the HITI donor vector in gene integration at target sites is approximately ten times higher than conventional HDRmediated methods [52]. The effectiveness of HITI in nonproliferating cells (primary mouse neurons), results in gene insertion in $60 \%$ of transfected cells. Because NHEJ is active throughout the cell cycle, non-dividing cells, which are in the G0/G1 phase, also harbor NHEJ activity [53]. This study also confirmed the results of previous studies by providing successful integration of marker genes in the $\mathrm{CHO}$ genome. This integration resulted in the generation of caspase 7 knockout $\mathrm{CHO}$ cell lines.

\section{Conclusion}

$\mathrm{CHO}$ cells are among the most critical host cells for the industrial production of therapeutics. Various strategies include a combination of metabolite nutrients, bioreactor process optimization, as well as the construction of high producing cell lines that are used to improve the $\mathrm{CHO}$ cell line. Targeting apoptosis-related genes may enhance the longevity of $\mathrm{CHO}$ within a culture which may subsequently improve the yield of biopharmaceutics. Executive caspases such as caspase 7 are deemed as essential proteins in the apoptosis pathway which are inducible by different stimuli. However, it has become evident that targeting these genes has propagated undesirable effects on $\mathrm{CHO}$ cell proliferation and viability. This demonstrates 
Table 1 The sequence of gRNAs and primers

\begin{tabular}{|c|c|c|}
\hline Oligoes & Caspase 7 target site & sequences \\
\hline Exon 4 & agatggcgtgacgccaataa & $\begin{array}{l}\text { Fw: CACCgAGATGGCGTGACGCCAATAA } \\
\text { Rev: AAACTTATTGGCGTCACGCCATCT }\end{array}$ \\
\hline Exon $4+$ PAM & agatggcgtgacgccaataaagg & $\begin{array}{l}\text { Fw: caccgCCTTTATTGGCGTCACGCCATCT } \\
\text { Rev: aaacAGATGGCGTGACGCCAATAAAGGC }\end{array}$ \\
\hline Exon 5 & gatacgctttaggcatgccg & $\begin{array}{l}\text { Fw: CACCGATACGCTTTAGGCATGCCG } \\
\text { Rev: AAACCGGCATGCCTAAAGCGTATC }\end{array}$ \\
\hline Exon $5+$ PAM & gatacgctttaggcatgccgagg & $\begin{array}{l}\text { Fw: caccCCTCGGCATGCCTAAAGCGTATC } \\
\text { Rev:aaacGATACGCTTTAGGCATGCCGAGG }\end{array}$ \\
\hline PX-460-1 primers & - & $\begin{array}{l}\text { Fwd: GCCTTTTGCTGGCCTTTTGCTC } \\
\text { Rev:CGGGCCATTTACCGTAAGTTATGTAACG }\end{array}$ \\
\hline Genomic primers & - & $\begin{array}{l}\text { Fwd: CTGAGGAGGACCACAGCAACTC } \\
\text { Rev: AACTGTGGAGTAAGCGAAGAGAA }\end{array}$ \\
\hline
\end{tabular}

that executive caspases are imperfect targets for improving viability.

\section{Material and methods}

\section{Cell lines and culture conditions}

$\mathrm{CHO}$ cell lines were obtained from the Pasture Institute (Tehran, Iran). Cells were cultured in DMEM high-glucose (Gibco, USA) supplemented with FBS (10\%), glutamine $(4.05 \mathrm{mM})$, penicillin, and streptomycin (100 IU). Cultures were preserved in a humidified incubator at $37^{\circ} \mathrm{C}$ with $5 \% \mathrm{CO}_{2}$.

\section{sgRNAs, plasmids and cloning}

In order to efficiently target the CASP-7 by knocking out/ in, CRISPR guide sequences were selected using CRISPy software. To this end, designing was based on targeting exons with a high efficient (high on-target score) and high specific (low off-target effects) sgRNAs. In this study, sgRNAs were chosen for targeting the active site of the CASP-7, which flanks in exons 4 and 5. Sequences for sgRNA oligos can be found in Table 1. For the silencing CASP-7, we combined the CRISPR multiplex system and HITI strategy. Plasmids for the multiplex CRISPR/Cas9 vectors include pX330S-2 (Plasmid \#58778, addgene, USA) and pX330A-1 $\times 2$ (Plasmid \#58766, addgene, USA), and the vector used for HITI strategy was PX460-1 which contains U6 promoter-sgRNA insertion site-sgRNA scaffold and CAG promoter-enhanced GFP (EGFP)-bovine growth hormone polyadenylation signal (gifted by Dena Zist company, Mashhad, Iran).

As previously described, the gRNAs targeting exons 4 and 5 were cloned in a single pX330A- $1 \times 2$ by using a golden gate assembly kit [54] and HITI gRNAs, which contained PAM sequence (Table 1) were cloned in pX460-1 vectors [52].
Transfection, single cell cloning and detection of CRISPR mediated knockout clone by PCR and sequencing $\mathrm{CHO}$ cells were co-transfected with pX330A-1×2 and pX460-1 plasmids using transfectimin as a transfection reagent based on the manufacture manual. Passing a week and after several passages, the GFP positive cells were sorted by FACS (BD) Cell Sorter. The permanent GFP expressing single-cell clones were grown and screened via PCR for caspase $7 \mathrm{KO}$ detection.

\section{Western blotting}

In order to confirm the knockout of CASP-7 in $\mathrm{CHO}$ cell line, SDS-PAGE electrophoresis followed by western blotting was performed. $\mathrm{CHO}-\mathrm{K} 1$ and $\mathrm{CHO}-\mathrm{KO}$ cells $\left(1 * 10^{6} /\right.$ culture flask $\left.\left[75 \mathrm{~cm}^{2}\right]\right)$ were treated with $\mathrm{NaBu}$ for 5 days with the concentration of $11 \mathrm{mM} / \mathrm{mL}$. Cells were harvested in amount of $5 \times 10^{6}$ by tripsinization and lysed with RIPA buffer and sonication. Proteins obtained from cell lysates were dissected by $8 \%$ SDS-polyacrylamide gel electrophoresis (PAGE) and transferred to PVDF membranes (Millipore, Bedford, MA). Caspase 7 was detected using anti-Caspase- 7 antibody (Abcam, Cat Nom: ab32522), respectively. Beta actin was used as an internal control that has a relatively uniform level of expression among different cells.

\section{Cell viability (MTT) and cell proliferation Assay}

The clone 4 of $\mathrm{CHO}-\mathrm{KO}$ and native $\mathrm{CHO}-\mathrm{K} 1$ cells were respectively plated in 96 wells plates with a concentration of $5 \times 10^{3}$ per well. The plates were kept in an incubator, and the cells were incubated for $16-24 \mathrm{~h}$ in standard drug-free growth medium to adhere to the surface of the plates. After the attachment, cells were exposed to $\mathrm{NaBu}$ at a designated concentration as 5, 7, 9, and $11 \mathrm{mM}$, respectively. The plates were put back to the incubator and kept for $1,2,3$, and 5 days at $37{ }^{\circ} \mathrm{C}$. After each respected day of incubation, the medium from each well 
was entirely removed and replaced with $100 \mu \mathrm{L}$ of fresh free culture medium containing $10 \mu \mathrm{L}$ of $12 \mathrm{mM}$ MTT stock solution. After $4 \mathrm{~h}$ of incubation, MTT media was replaced by $100 \mu \mathrm{L}$ of DMSO following mixing thoroughly using an orbit plate shaker. The plates were then incubating for additionally $10 \mathrm{~min}$, then the absorbance was read at 540 and $680 \mathrm{~nm}$ reference wavelengths. To assess the cell proliferation, parentral $\mathrm{CHO}-\mathrm{KO}$ cells and four single cell clones isolated from this cell line were seeded in 96 well plates in the mentioned concentration, and MTT assay was performed in days 1 and 5 (CHO-K1 single cell clones were used as control). Both these assays were repreated three times and in sextuplicate manner.

\section{Assessment of apoptosis by Annexin /PI staining}

This assay was used to measure the number of cells that have undergone apoptosis. In short, $0.5 \times 10^{6}$ cells were seeded in 6 well plates and treated with $\mathrm{NaBu}(11 \mathrm{mM})$ for 5 days. Cells were detached by trypsin and put in a polystyrene $75 \times 12 \mathrm{~mm}$ tube, washed with $1 \mathrm{~mL}$ icecold Annexin $\mathrm{V}$ binding buffer (10 mM HEPES, $140 \mathrm{mM}$ $\mathrm{NaCl}, 2.5 \mathrm{mM} \mathrm{CaCl}_{2}$ in $\mathrm{dH}_{2} \mathrm{O}, \mathrm{pH}$ 7.4), centrifuged, and re-suspended in $100 \mu \mathrm{L}$ binding buffer. $2.5 \mu \mathrm{L}$ of Annexin $\mathrm{V}$ was added per tube and incubated for $15 \mathrm{~min}$ in the fridge. $400 \mu \mathrm{L}$ of binding buffer was further added into the tube after incubation. Finally, $5 \mu \mathrm{L}$ of 7AAD $(20 \mu \mathrm{g} /$ $\mathrm{mL}$ stock) was added to each tube $45 \mathrm{~s}$ before the flow cytometric analysis. This assay was repeated two times.

\section{Abbreviations \\ CHO: Chinese hamster ovary; ZFNs: Zinc-finger nucleases; TALENs: Transcrip- tion activator-like effector nucleases; CRISPR: Clustered regularly interspaced short palindromic repeats; Cas: CRISPR-associated protein; NHEJ: Non-homolo- gous end joining; HDR: Homology-directed repair; HITI: Homology independ- ent targeted integration; EGFP: Enhanced green fluorescent protein; $\mathrm{NaBu}$ : Sodium butyrate; DSB: Double-strand DNA break.}

\section{Acknowledgements}

Authors would like to thank the Biotechnology Research Center, Tabriz University of Medical Sciences for supporting this project (Grant No. 94/4-2/4). This study was financially supported by Grant No: 950609 of the Biotechnology Development Council of the Islamic Republic of Iran.

\section{Authors' contributions}

FS: the main doer of the project who performed the designing of sgRNAs, cell culture, transfection, single cell cloning and MTT, SF: the designer and the supervisor of the project, $A B-B$ : he performed the flow cytometry, $H Z$ : he performed the statistical analysis, HD: he was the advisor of the project and he designed the HITI strategy for gene targeting. All authors read and approved the final manuscript.

\section{Funding}

Not applicable.

\section{Availability of data and materials}

The datasets used and/or analyzed during the current study are available from the corresponding author on reasonable request.

\section{Ethics approval and consent to participate}

Ethics approval for the study was obtained from an ethics committee of Tabriz University of Medical Sciences dated 2016/13/08, No: 5/4/46151.

\section{Consent for publication}

Not applicable.

\section{Competing interests}

Not applicable.

\section{Author details \\ ${ }^{1}$ Department of Medical Biotechnology, Faculty of Advanced Medical Sci- ences, Tabriz University of Medical Sciences, Tabriz, Iran. ${ }^{2}$ Biotechnology Research Center, Tabriz University of Medical Sciences, Daneshgah Ave., Tabriz, Iran. ${ }^{3}$ Diagnostic Laboratory Sciences and Technology Research Center, School of Paramedical Sciences, Shiraz University of Medical Sciences, Shiraz, Iran. ${ }^{4}$ Tuberculosis and Lung Diseases Research Center, Tabriz University of Medical Sciences, Tabriz, Iran. ${ }^{5}$ Department of Physiology \& Biophysics, School of Medicine, Case Western Reserve University, Cleveland, Ohio, USA. ${ }^{6}$ Department of Basic Sciences, Faculty of Veterinary Medicine, Ferdowsi University of Mashhad, Mashhad, Iran. ${ }^{7}$ Drug Applied Research Center, Tabriz University of Medical Sciences, Tabriz, Iran.}

Received: 5 June 2020 Accepted: 4 November 2020

Published online: 13 November 2020

\section{References}

1. Mulukutla BC, Kale J, Kalomeris T, Jacobs M, Hiller GW. Identification and control of novel growth inhibitors in fed-batch cultures of Chinese hamster ovary cells. Biotechnol Bioeng. 2017;114(8):1779-90.

2. Walsh G. Biopharmaceutical benchmarks 2014. Nat Biotechnol. 2014;32(10):992-1000.

3. Lee N, Shin J, Park JH, Lee GM, Cho S, Cho BK. Targeted gene deletion using DNA-Free RNA-guided Cas9 nuclease accelerates adaptation of CHO cells to suspension culture. ACS Synth Biol. 2016;5(11):1211-9.

4. Usaj M, Zattelman L, Regev R, Shneyer BI, Wiesel-Motiuk N, Henn A. Overexpression and purification of human myosins from transiently and stably transfected suspension adapted HEK293SF-3F6 cells. Anal Biochem. 2018;558:19-27.

5. Cost GJ, Freyvert Y, Vafiadis A, Santiago Y, Miller JC, Rebar E, et al. BAK and $\mathrm{BAX}$ deletion using zinc-finger nucleases yields apoptosis-resistant $\mathrm{CHO}$ cells. Biotechnol Bioeng. 2010;105(2):330-40.

6. Albrecht S, Kaisermayer C, Gallagher C, Farrell A, Lindeberg A, Bones J. Proteomics in biomanufacturing control: protein dynamics of $\mathrm{CHO}-\mathrm{K}$ cells and conditioned media during apoptosis and necrosis. Biotechnol Bioeng. 2018;115(6):1509-20.

7. Krampe B, Al-Rubeai M. Cell death in mammalian cell culture: molecular mechanisms and cell line engineering strategies. Cytotechnology. 2010;62(3):175-88.

8. Sung YH, Lee JS, Park SH, Koo J, Lee GM. Influence of co-down-regulation of caspase-3 and caspase- 7 by siRNAs on sodium butyrate-induced apoptotic cell death of Chinese hamster ovary cells producing thrombopoietin. Metab Eng. 2007;9(5-6):452-64.

9. Zarredar H, Pashapour S, Farajnia S, Ansarin K, Baradaran B, Ahmadzadeh $V$, et al. Targeting the KRAS, p38alpha, and NF-kappaB in lung adenocarcinoma cancer cells: the effect of combining RNA interferences with a chemical inhibitor. J Cell Biochem. 2019;120(6):10670-7.

10. Safari F, Rahmani Barouji S, Tamaddon AM. Strategies for improving siRNA-induced gene silencing efficiency. Adv Pharm Bull. 2017;7(4):603-9.

11. Safari F, Tamaddon AM, Zarghami N, Abolmali S, Akbarzadeh A. Polyelectrolyte complexes of hTERT siRNA and polyethyleneimine: effect of degree of PEG grafting on biological and cellular activity. Artif Cells Nanomed Biotechnol. 2016;44(6):1561-8.

12. Lee JS, Grav LM, Lewis NE, Faustrup KH. CRISPR/Cas9-mediated genome engineering of $\mathrm{CHO}$ cell factories: application and perspectives. Biotechnol J. 2015;10(7):979-94.

13. Urnov FD, Rebar EJ, Holmes MC, Zhang HS, Gregory PD. Genome editing with engineered zinc finger nucleases. Nat Rev Genet. 2010;1 1(9):636-46. 
14. Su X, Wang S, Su G, Zheng Z, Zhang J, Ma Y, et al. Production of microhomologous-mediated site-specific integrated LacS gene cow using TALENs. Theriogenology. 2018;119:282-8.

15. Silva G, Poirot L, Galetto R, Smith J, Montoya G, Duchateau P, et al. Meganucleases and other tools for targeted genome engineering: perspectives and challenges for gene therapy. Curr Gene Ther. 2011;11(1):11-27.

16. Kawabe Y, Komatsu S, Komatsu S, Murakami M, Ito A, Sakuma T, et al. Targeted knock-in of an scFv-Fc antibody gene into the hprt locus of Chinese hamster ovary cells using CRISPR/Cas9 and CRIS-PITCh systems. J Biosci Bioeng. 2018;125(5):599-605.

17. Safari F, Farajnia S, Ghasemi Y, Zarghami N. New developments in CRISPR technology: improvements in specificity and efficiency. Curr Pharm Biotechnol. 2017;18(13):1038-54.

18. Safari F, Hatam G, Behbahani AB, Rezaei V, Barekati-Mowahed M, Petramfar P, et al. CRISPR system: a high-throughput toolbox for research and treatment of Parkinson's disease. Cell Mol Neurobiol. 2019:40:477-93.

19. Farajnia S, Ghasemi Y, Zarghami N, Barekati-Mowahed M. Multiplex genome Engineering in Chinese hamster ovary cells using all-in-one and HITI CRISPR technology. Adv Pharm Bull. 2020.

20. Safari F, Farajnia S, Arya M, Zarredar H, Nasrolahi A. CRISPR and personalized Treg therapy: new insights into the treatment of rheumatoid arthritis. Immunopharmacol Immunotoxicol. 2018;40(3):201-11.

21. Safari F, Sharifi M, Farajnia S, Akbari B, Karimi Baba Ahmadi M, Negahdaripour $M$, et al. The interaction of phages and bacteria: the co-evolutionary arms race. Crit Rev Biotechnol. 2020;40(2):119-37.

22. Safari F, Zare K, Negahdaripour M, Barekati-Mowahed M, Ghasemi Y. CRISPR Cpf1 proteins: structure, function and implications for genome editing. Cell Biosci. 2019;9:36.

23. Grav LM, Lee JS, Gerling S, Kallehauge TB, Hansen AH, Kol S, et al. Onestep generation of triple knockout $\mathrm{CHO}$ cell lines using CRISPR/Cas9 and fluorescent enrichment. Biotechnol J. 2015;10(9):1446-56.

24. Kim YG, Kim JY, Lee GM. Effect of XIAP overexpression on sodium butyrate-induced apoptosis in recombinant Chinese hamster ovary cells producing erythropoietin. J Biotechnol. 2009;144(4):299-303.

25. Baik JY, Joo EJ, Kim YH, Lee GM. Limitations to the comparative proteomic analysis of thrombopoietin producing Chinese hamster ovary cells treated with sodium butyrate. J Biotechnol. 2008;133(4):461-8.

26. Yin B, Wang Q, Chung CY, Ren X, Bhattacharya R, Yarema KJ, et al. Butyrated ManNAc analog improves protein expression in Chinese hamster ovary cells. Biotechnol Bioeng. 2018;115(6):1531-41.

27. Han S, Rhee WJ. Inhibition of apoptosis using exosomes in Chinese hamster ovary cell culture. Biotechnol Bioeng. 2018;115(5):1331-9.

28. Sung YH, Hwang SJ, Lee GM. Influence of down-regulation of caspase-3 by siRNAs on sodium-butyrate-induced apoptotic cell death of Chinese hamster ovary cells producing thrombopoietin. Metab Eng 2005;7(5-6):457-66.

29. Kim NS, Lee GM. Inhibition of sodium butyrate-induced apoptosis in recombinant Chinese hamster ovary cells by constitutively expressing antisense RNA of caspase-3. Biotechnol Bioeng. 2002;78(2):217-28.

30. Hwang SO, Lee GM. Effect of Akt overexpression on programmed cell death in antibody-producing Chinese hamster ovary cells. J Biotechnol. 2009;139(1):89-94.

31. Wong DC, Wong KT, Nissom PM, Heng CK, Yap MG. Targeting early apoptotic genes in batch and fed-batch $\mathrm{CHO}$ cell cultures. Biotechnol Bioeng. 2006:95(3):350-61.

32. Xiong K, Marquart KF, la Cour KKJ, Li S, Shamie I, Lee JS, et al. Reduced apoptosis in Chinese hamster ovary cells via optimized CRISPR interference. Biotechnol Bioeng. 2019;116(7):1813-9.

33. Yun CY, Liu S, Lim SF, Wang T, Chung BY, Jiat Teo J, et al. Specific inhibition of caspase-8 and -9 in CHO cells enhances cell viability in batch and fedbatch cultures. Metab Eng. 2007;9(5-6):406-18.

34. Connolly P, Garcia-Carpio I, Villunger A. Cell-cycle cross talk with caspases and their substrates. Cold Spring Harb Perspect Biol. 2020;12(6):a036475.

35. Fattman CL, Delach SM, Dou QP, Johnson DE. Sequential two-step cleavage of the retinoblastoma protein by caspase-3/-7 during etoposideinduced apoptosis. Oncogene. 2001;20(23):2918-26.
36. Jänicke RU, Walker PA, Lin XY, Porter AG. Specific cleavage of the retinoblastoma protein by an ICE-like protease in apoptosis. EMBO J. 1996;15(24):6969-78.

37. Matsuura K, Wakasugi M, Yamashita K, Matsunaga T. Cleavage-mediated activation of Chk1 during apoptosis. J Biol Chem. 2008;283(37):25485-91.

38. Okita N, Yoshimura M, Watanabe K, Minato S, Kudo Y, Higami Y, et al. $\mathrm{CHK} 1$ cleavage in programmed cell death is intricately regulated by both caspase and non-caspase family proteases. Biochim Biophys Acta. 2013;1830(1):2204-13.

39. Hashimoto T, Kikkawa U, Kamada S. Contribution of caspase(s) to the cell cycle regulation at mitotic phase. PLoS ONE. 2011;6(3):e18449.

40. Cardona M, Lopez JA, Serafin A, Rongvaux A, Inserte J, Garcia-Dorado D, et al. Executioner caspase-3 and 7 deficiency reduces myocyte number in the developing mouse heart. PLoS ONE. 2015;10(6):e0131411.

41. Svandova E, Lesot H, Vanden Berghe T, Tucker AS, Sharpe PT, Vandenabeele $\mathrm{P}$, et al. Non-apoptotic functions of caspase-7 during osteogenesis. Cell Death Dis. 2014;5(8):e1366.

42. Datta P, Yang B, Linhardt RJ, Sharfstein ST. Modulation of heparan sulfate biosynthesis by sodium butyrate in recombinant $\mathrm{CHO}$ cells. Cytotechnology. 2015;67(2):223-35.

43. Salimi V, Shahsavari Z, Safizadeh B, Hosseini A, Khademian N, TavakoliYaraki M. Sodium butyrate promotes apoptosis in breast cancer cells through reactive oxygen species (ROS) formation and mitochondrial impairment. Lipids Health Dis. 2017;16(1):208.

44. Hausmann G, O'Reilly LA, van Driel R, Beaumont JG, Strasser A, Adams $J M$, et al. Pro-apoptotic apoptosis protease-activating factor 1 (Apaf-1) has a cytoplasmic localization distinct from Bcl-2 or BCl-x(L). J Cell Biol. 2000;149(3):623-34.

45. Marsden VS, O'Connor L, O'Reilly LA, Silke J, Metcalf D, Ekert PG, et al. Apoptosis initiated by $\mathrm{BCl}$-2-regulated caspase activation independently of the cytochrome c/Apaf-1/caspase-9 apoptosome. Nature. 2002;419(6907):634-7.

46. Lakhani SA, Masud A, Kuida K, Porter GA Jr, Booth CJ, Mehal WZ, et al. Caspases 3 and 7: key mediators of mitochondrial events of apoptosis. Science. 2006;311(5762):847-51.

47. Kumar N, Afjei R, Massoud TF, Paulmurugan R. Comparison of cell-based assays to quantify treatment effects of anticancer drugs identifies a new application for Bodipy-L-cystine to measure apoptosis. Sci Rep. 2018;8(1):16363.

48. Lotze MT, Thomson AW. Measuring Immunity: basic science and clinical practice. Amsterdam: Elsevier; 2011.

49. Sauerwald TM, Oyler GA, Betenbaugh MJ. Study of caspase inhibitors for limiting death in mammalian cell culture. Biotechnol Bioeng. 2003;81(3):329-40.

50. Henry MN, MacDonald MA, Orellana CA, Gray PP, Gillard M, Baker K, et al. Attenuating apoptosis in Chinese hamster ovary cells for improved biopharmaceutical production. Biotechnol Bioeng. 2020;117(4):1187-203.

51. Suzuki K, Izpisua Belmonte JC. In vivo genome editing via the HITI method as a tool for gene therapy. J Hum Genet. 2018;63(2):157-64.

52. Zare K, Shademan M, Ghahramani Seno MM, Dehghani H. CRISPR/Cas9 knockout strategies to ablate CCAT1 IncRNA gene in cancer cells. Biol Proced Online. 2018;20:21.

53. Suzuki K, Tsunekawa Y, Hernandez-Benitez R, Wu J, Zhu J, Kim EJ, et al. In vivo genome editing via CRISPR/Cas9 mediated homology-independent targeted integration. Nature. 2016;540(7631):144-9.

54. Sakuma T, Nishikawa A, Kume S, Chayama K, Yamamoto T. Multiplex genome engineering in human cells using all-in-one CRISPR/Cas9 vector system. Sci Rep. 2014;4:5400.

\section{Publisher's Note}

Springer Nature remains neutral with regard to jurisdictional claims in published maps and institutional affiliations. 